\title{
Prevalence of plasma lipid disorders with an emphasis on LDL cholesterol in selected countries in the Asia-Pacific region
}

\author{
Zhen-Vin Lee ${ }^{1}$, Elmer Jasper Llanes ${ }^{2}$, Renan Sukmawan ${ }^{3}$, Nuntakorn Thongtang ${ }^{4}$, Huynh Quang Tri Ho ${ }^{5}$, \\ Philip Barter ${ }^{6^{*}}$, on behalf of the Cardiovascular RISk Prevention (CRISP) in Asia Network
}

\begin{abstract}
Cardiovascular disease (CVD) is a major cause of mortality and morbidity within the Asia-Pacific region, with the prevalence of CVD risk factors such as plasma lipid disorders increasing in many Asian countries. As members of the Cardiovascular RISk Prevention (CRISP) in Asia network, the authors have focused on plasma lipid disorders in the six countries within which they have clinical experience: Indonesia, Malaysia, Philippines, Thailand, Vietnam, and Australia. Based on country-specific national surveys, the prevalence of abnormal levels of total cholesterol, low- and high-density lipoprotein cholesterol (LDL-C and HDL-C, respectively), and triglycerides (TG) are reported. An important caveat is that countries have used different thresholds to define plasma lipid disorders, making direct comparisons difficult. The prevalence of abnormal lipid levels was as follows: high total cholesterol (30.2-47.7\%, thresholds: 190-213 mg/dL); high LDL-C (33.2-47.5\%; thresholds: 130-135 mg/dL); low/abnormal HDL-C (22.9-72.0\%; thresholds: 39-50 mg/dL); and high/abnormal TG (13.9-38.7\%; thresholds: 150-177 mg/dL). Similarities and differences between country-specific guidelines for the management of plasma lipid disorders are highlighted. Based on the authors' clinical experience, some of the possible reasons for suboptimal management of plasma lipid disorders in each country are described. Issues common to several countries include physician reluctance to prescribe high-dose and/or high-intensity statins and poor understanding of disease, treatments, and side effects among patients. Treatment costs and geographical constraints have also hampered disease management in Indonesia and the Philippines. Understanding the factors governing the prevalence of plasma lipid disorders helps enhance strategies to reduce the burden of CVD in the Asia-Pacific region.
\end{abstract}

Keywords: Asia-Pacific, Dyslipidemia, Guidelines, Plasma lipid disorders, Prevalence

\section{Introduction}

Cardiovascular disease (CVD) is one of the most prevalent and debilitating chronic diseases, and approximately half of the global burden of CVD is located in the AsiaPacific region [1]. Further, the burden of CVD and plasma lipid disorders is increasing across the AsiaPacific region [1, 2]. Age-standardized death rates per

\footnotetext{
* Correspondence: pbarter@ozemail.com.au

${ }^{6}$ School of Medical Sciences, University of New South Wales, Sydney, NSW, Australia

Full list of author information is available at the end of the article
}

100,000 for CVD in several Asian countries are among the highest in the world (Fig. 1). Further, the ageadjusted mortality due to cerebrovascular disease (stroke) in many Asian countries is higher than in some Western countries [1]. While age-specific CVD is declining in many high-income countries in other parts of the world, this is not the case in most of Asia [2, 4, 5].

The prevalence of specific risk factors for CVD among Asian populations differs from Western populations in the same geographical region, such as Australia and New Zealand [6]. High blood pressure and high rates of

C C The Author(s). 2021 Open Access This article is licensed under a Creative Commons Attribution 4.0 International License, which permits use, sharing, adaptation, distribution and reproduction in any medium or format, as long as you give appropriate credit to the original author(s) and the source, provide a link to the Creative Commons licence, and indicate if changes were made. The images or other third party material in this article are included in the article's Creative Commons licence, unless indicated otherwise in a credit line to the material. If material is not included in the article's Creative Commons licence and your intended use is not permitted by statutory regulation or exceeds the permitted use, you will need to obtain permission directly from the copyright holder. To view a copy of this licence, visit http://creativecommons.org/licenses/by/4.0/ The Creative Commons Public Domain Dedication waiver (http://creativecommons.org/publicdomain/zero/1.0/) applies to the data made available in this article, unless otherwise stated in a credit line to the data. 


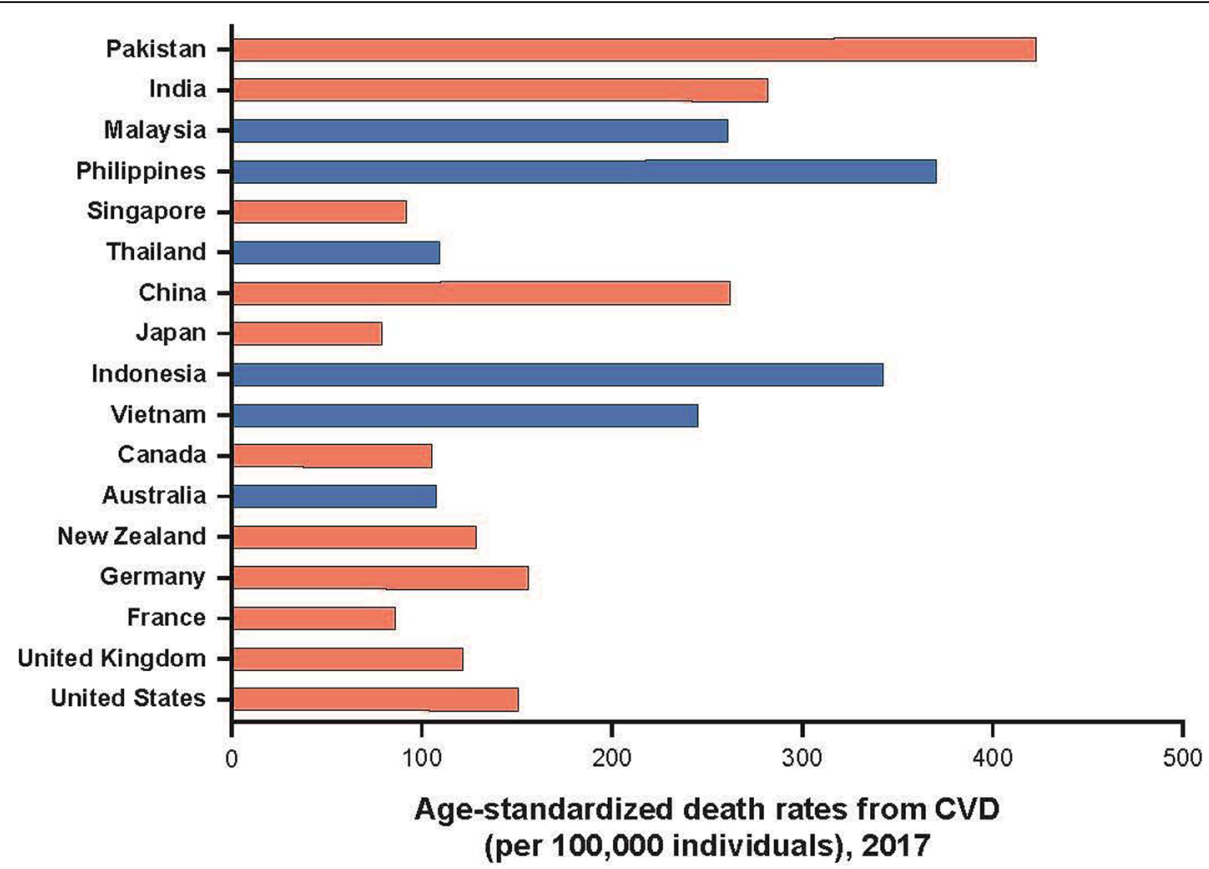

Fig. 1 Age-standardized death rates per 100,000 from CVD [3]. Data from countries of interest are represented as black bars. Abbreviation: CVD cardiovascular disease

smoking appear to be more prevalent in Asia whereas high plasma cholesterol (Fig. 2) and high body mass index (BMI) are more prevalent in Australia and New Zealand. However, the overall prevalence of cardiovascular (CV) risk factors is increasing across Asia, including plasma lipid disorders, obesity, and type 2 diabetes mellitus $[7,8]$. A recent analysis by the NCD Risk Factor Collaboration suggested that from 1980 to 2018, the countries with the highest levels of non-HDL cholesterol had shifted from being countries in western Europe to those in Asia and the Pacific (including Malaysia, the Philippines, and Thailand) [9].

The Cardiovascular RISk Prevention (CRISP) in Asia network was convened in 2018 to gather clinical experts from different countries in the Asia-Pacific region. By sharing clinical insights and expertise across countries, the CRISP in Asia network aims to develop strategies to tackle the rising burden of CVD in the region. As members of the CRISP in Asia network, the authors' aim for this review is to highlight the prevalence of plasma lipid

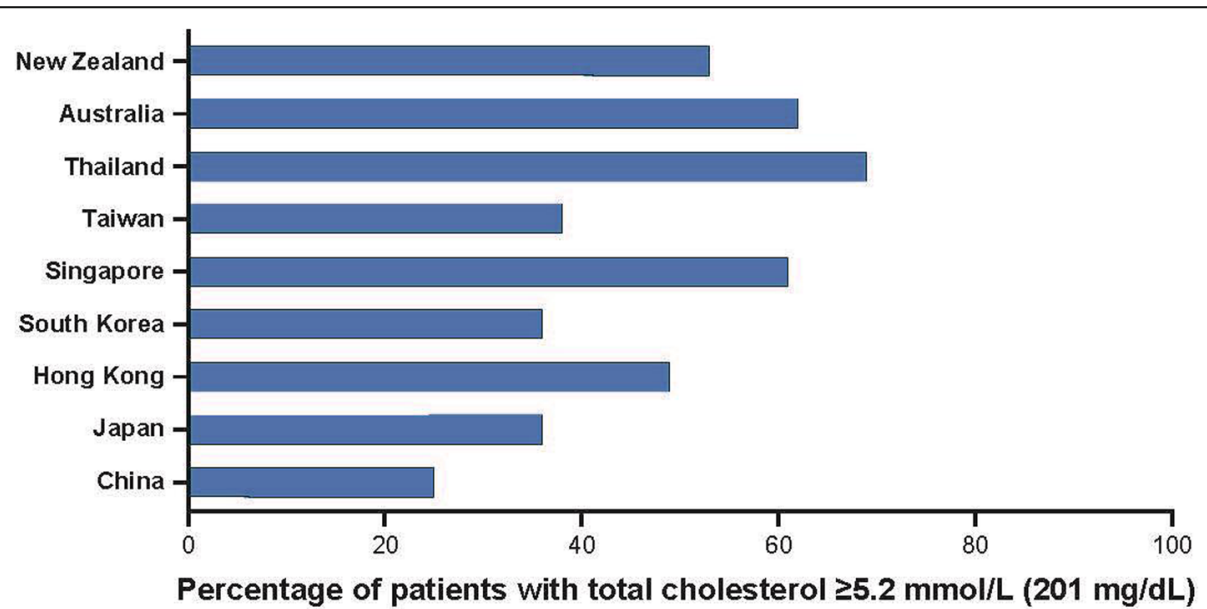

Fig. 2 Percentage of patients with elevated total cholesterol in Asia and Australia/New Zealand [6] ${ }^{*}$ *Only studies from the Asia-Pacific Cohort Studies Collaboration that meet pre-defined criteria were used to generate these data [6]. The prevalence of plasma lipid disorders based on national survey data from Indonesia, Malaysia, Philippines, Thailand, Vietnam, and Australia is presented in Table 1 
disorders in selected Asian countries, with a specific focus on low-density lipoprotein cholesterol (LDL-C). In contrast to many previous studies, this review uses data from national surveys conducted in a cross-section of the general population, which the authors believe to be one of the best methods to obtain accurate estimates of the true prevalence of lipid disorders. The analysis concentrates primarily on the five countries in which the authors live and practice (Indonesia, Malaysia, Philippines, Thailand, and Vietnam), with Australia serving as a useful reference, being a representative Western country in the same region. As medical practitioners in these six countries, the authors are able to draw upon their clinical experience with patients with plasma lipid disorders. The review also describes country-specific guidelines that have been developed to reduce the prevalence and burden of plasma lipid disorders as well as the issues hampering these efforts. This review is not intended to be a set of guidelines but rather serves as a snapshot of the current state of plasma lipid disorders in selected Southeast Asian countries and Australia.

\section{Plasma lipid disorders}

The term plasma lipid disorders, as used in this review, refers to abnormal levels of lipids in the blood, including LDL-C, high-density lipoprotein cholesterol (HDL-C), and triglycerides, which may lead to increased $\mathrm{CV}$ risk [10-12]. In Western populations, plasma lipid disorders typically refer to high LDL-C levels that are associated with increased $\mathrm{CV}$ risk. However, studies have shown an increased prevalence of low HDL-C and high triglyceride levels in Asian populations in comparison with Western populations, which may also be associated with increasing CV risk $[5,13,14]$. Treatment guidelines, which are often based on data from Western populations, typically focus on achieving low LDL-C and CV risk [15, 16]. Therefore, for the purposes of this review, the focus is predominantly on elevated LDL-C.

\section{Prevalence of plasma lipid disorders in selected countries in the Asia-Pacific region}

Several studies evaluating the prevalence and management of plasma lipid disorders in the Asia-Pacific region have been conducted in recent years [17-33]. Many of these studies focus on specific subsets of a population, sampling only urban residents [17], or workers [22] or patients who are already receiving treatment for dyslipidemia [23], which may not reflect the prevalence within the general population of a particular country. A substantial proportion of people with dyslipidemia may not even be aware of their condition. Therefore, a more accurate estimate of the true prevalence can be gauged from surveys in which lipid levels are monitored in a cross-section of the general population. For this reason, the authors chose to use data from the most recent national surveys conducted in each country (Table 1); these surveys were usually undertaken by government agencies. Compared with specialized studies of prevalence, national surveys often have a larger sample size, cover a range of geographical areas (urban and rural), and sample both healthy and affected individuals.

National survey data for each of the six countries above were provided by the authors or were obtained by web searches of the publicly available resources for the relevant organizations in each country (e.g., Australian Bureau of Statistics, Ministry of Health of Republic of Indonesia, Ministry of Health: General Department of Preventative Medicine [Vietnam]). In order to be included in this publication, the survey data had to satisfy the following criteria: (1) data had to have been collected within the last 10 years by a government agency, (2) sampling had to be performed on the general population (instead of a focus on patients with a confirmed diagnosis) in both urban and rural areas, (3) data had to contain information on the prevalence of high/abnormal total cholesterol, as well as other relevant lipid parameters. The relevant data were extracted (categories were translated to English if required) and tabulated as shown in Table 1. Data on familial hypercholesterolemia were not present in surveys from every country so were not included in the present analysis.

It is important to note that because some countries have used different thresholds to define plasma lipid disorders, it is difficult to compare the prevalence of these disorders across countries. As such, we have reported the prevalence of lipid disorders for each country (where available) but have refrained from making comparisons between countries. At least $30 \%$ of participants sampled in all six countries had high total cholesterol (thresholds range $190-213 \mathrm{mg} / \mathrm{dL}$ ) (Table 1). The prevalence of high total cholesterol ranged from $30.2 \%$ (Vietnam) to $47.7 \%$ (Malaysia). Among the three countries with data collected for LDL-C, the prevalence of high LDL-C was 33.2\% for Australia, $41.9 \%$ for Indonesia, and $47.5 \%$ for the Philippines (Table 1); all three countries employed similar thresholds to define high LDL-C. The five countries that collected data on the prevalence of low HDL-C were Australia (23.1\%), Indonesia (22.9\%), the Philippines (71\%), Thailand (40.3\%), and Vietnam [67\% (males); 72\% (females)]. The prevalence of high triglycerides was reported for Australia (13.9\%), Indonesia (24.9\%), the Philippines (38.7\%), and Thailand (31.0\%).

A number of countries also examined the differences in the prevalence of lipid disorders among different subgroups. In all six countries, the prevalence of high total cholesterol was numerically higher in females compared with males (Table 1), with the largest differences ( 9\%) observed in Indonesia, the Philippines, and Vietnam. 


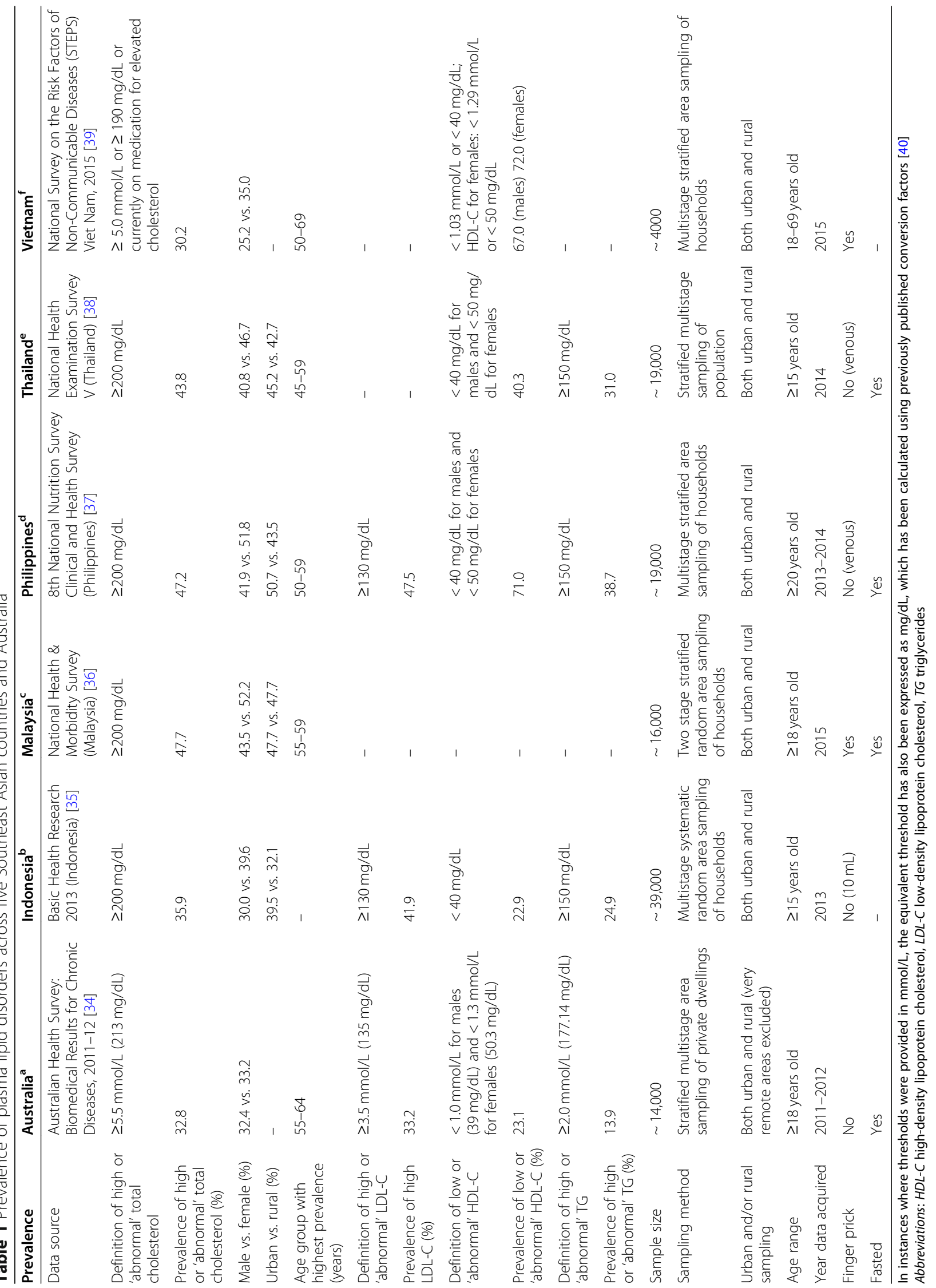


Prevalence also appeared to be highest in the age brackets between 50 and 69 years, for Australia, Malaysia, the Philippines, and Vietnam (Table 1). In Thailand, the 45-59-year age group had the highest prevalence of high total cholesterol. In terms of socioeconomic status, the prevalence of borderline to high total cholesterol in the Philippines was observed to increase with the wealth of respondents (poorest quintile: $33.0 \%$ vs richest quintile: $57.8 \%$ ); a similar trend was observed for the prevalence of LDL-C. In Malaysia, the prevalence of high total cholesterol was similar across all household income quintiles (46.0-52.2\%).

Although the data reported for all six countries come from national surveys, there were important differences in the way that the surveys were carried out, which may affect the estimated prevalence. For example, Lin and coauthors described several factors that can affect the validity of comparing study findings, including the age range of participants, lipid testing methods, medications used, year of data acquisition, and definition of dyslipidemia used for each study [23].

Data from all six countries were collected during a similar period (2011-2015) and were from both urban and rural populations (Table 1). The survey sample sizes were similar for Australia, Malaysia, the Philippines, and Thailand (between 14,000 and 19,000), while a much larger sample was surveyed in Indonesia $(\sim 39,000)$ and a much smaller sample surveyed in Vietnam $(\sim 4000)$. The minimum age of participants was between 18 and 20 years for Australia, Malaysia, the Philippines, and Vietnam, while participants in Indonesia and Thailand had lower minimum ages ( $\geq 15$ years old). There were notable differences in blood sampling methods across countries, with finger prick sampling employed in Malaysia and Vietnam but not in the other countries, which mostly used venous sampling.

\section{Guidelines for improving the management of plasma lipid disorders}

Given the prevalence of plasma lipid disorders in Asian and Western countries, several international guidelines have been developed to reduce CV risk; these guidelines are based on robust evidence, largely from randomized controlled clinical trials. Clinical practice guidelines to reduce $\mathrm{CV}$ risk are available from international committees such as the European Society of Cardiology (ESC) and European Atherosclerosis Society (EAS) [16] and the recently published $2018 \mathrm{AHA} / \mathrm{ACC} / \mathrm{AACVPR} /$ AAPA/ABC/ACPM/ADA/AGS/APhA/ASPC/NLA/ PCNA guidelines [15]. These major international guidelines served as the basis for the development of countryspecific guidelines. Indonesia [41], Malaysia [42], the Philippines [43], Thailand [44], and Vietnam [45] have all developed local guidelines (Table 2). However, given that the development of these international guidelines was based mainly on clinical trial data from Western populations, their applicability to Asian countries needs to be confirmed.

In addition to country-specific or regional guidelines, there are also expert panel recommendations on the use of international guidelines in Asia [5]. A 2018 expert panel (which included Philip Barter and Nuntakorn Thongtang) noted that the 2016 ESC/EAS guidelines have introduced specific LDL-C goals for different risk groups and promote lifestyle intervention (considered generally applicable to the management of plasma lipid disorders in Asia-Pacific). The 2014 National Institute for Health and Care Excellence UK guidelines [47] were considered by the panel to be applicable in Malaysia, the Philippines, Thailand, and Indonesia.

The expert panel concluded that LDL-C is an important $\mathrm{CV}$ risk factor, with the failure to attain optimal lipid levels contributing significantly to the residual risk of CVD and that therefore, LDL-C should be a primary therapeutic target. The panel also recommended that there should be a major emphasis on lifestyle intervention, whether or not drug therapy is used, and the decision to use lipid-lowering drugs should be based on an assessment of overall CV risk rather than on any perceived need to treat an abnormal lipid level. Lastly, the panel also recognized the potential for less intensive statin therapy to be used in the Asian population [5] and recommended that local guidelines be developed that are appropriate for the local populations [5, 48].

However, since these panel recommendations were published, both major international guidelines have been updated, with the 2018 AHA/ACC and the 2019 ESC/ EAS guidelines being the most recent. The panel did not consider the Vietnamese guidelines nor the most recent update to the Indonesian guidelines, which occurred in 2017. Compared with the 2013 AHA/ACC guidelines, the 2018 AHA/ACC guidelines recommended the addition of ezetimibe for those receiving maximal statin therapy with LDL-C still $\geq 70 \mathrm{mg} / \mathrm{dL}$ [15]. If needed, PCSK9 inhibitors were recommended for patients with very high clinical atherosclerotic CVD risk. Similarly, the revised 2019 ESC/EAS guidelines recommended the addition of ezetimibe when LDL-C goal is not achieved with the maximum tolerated dose of statin. In terms of secondary prevention, the addition of a PCSK9 inhibitor was recommended for very high-risk patients not at goal despite treatment with the maximum tolerated dose of statins and ezetimibe.

\section{Comparison of local guidelines for management of plasma lipid disorders}

The use of major international guidelines as a basis for the development of country-specific guidelines has 


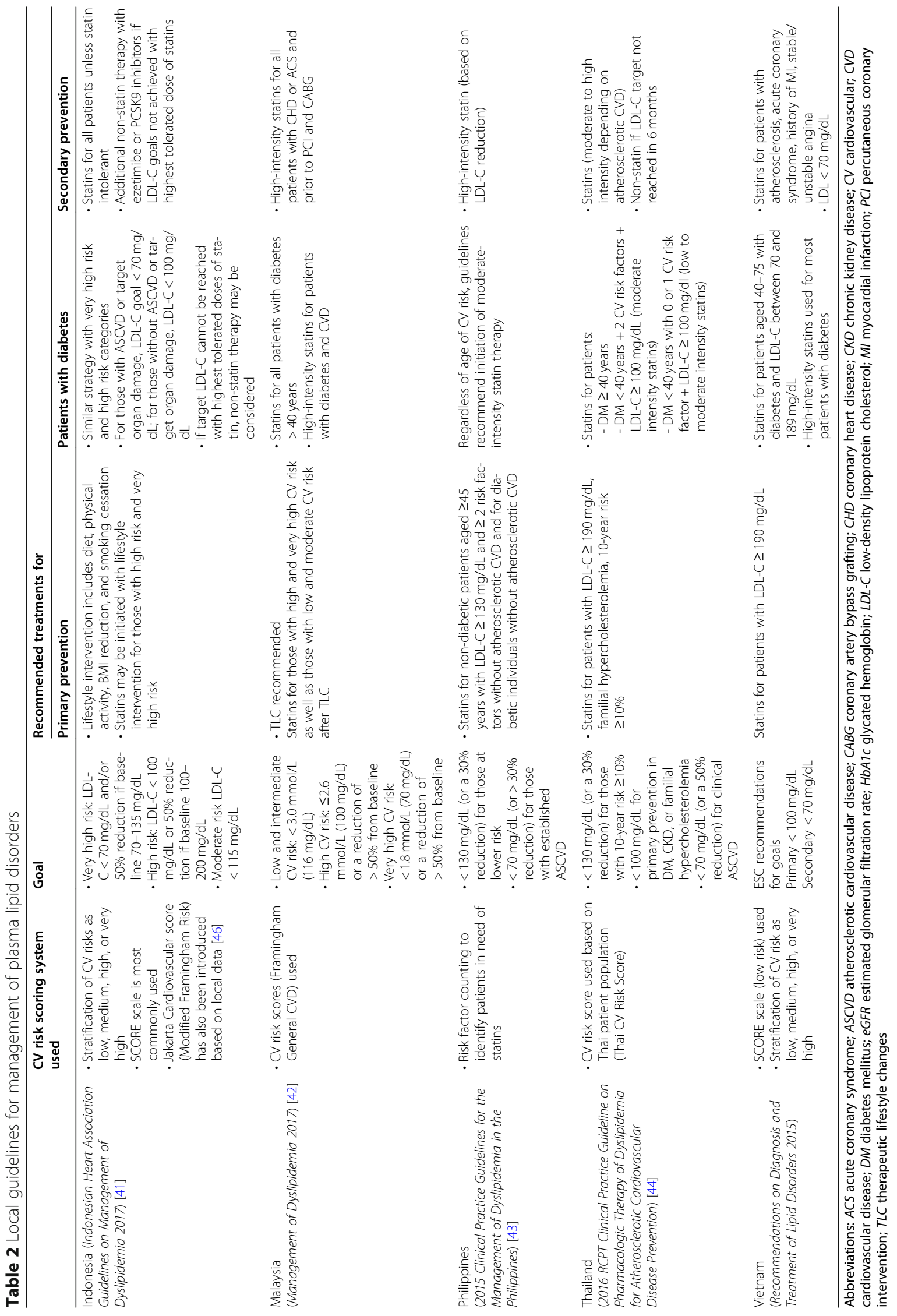


resulted in a number of similarities between the guidelines of the Asian countries being discussed. Almost all countries recommended the use of a risk scoring system to estimate CV risk (Table 2). The exception was the Philippines, which recommended risk factor counting due to concerns that CV risk calculators based on Western patients were not validated in the Filipino population. Similar concerns were raised in Malaysia, where a recent study examined the validity of different riskprediction models, concluding that the Framingham Risk Score and the SCORE-high risk models could be used in the Malaysian population [49]. The SCORE-low risk model is used to estimate the 10-year risk of fatal CVD in Vietnam [45]. Unlike most of the other countries, the $\mathrm{CV}$ risk score used in Thailand has been validated in a local Thai patient population [50]. All countries had specific LDL-C goals that depended on an individual's level of CV risk (Table 2). Most countries recommend LDL-C $<70 \mathrm{mg} / \mathrm{dL}$ for those at highest CV risk and LDL-C $<116$ to $130 \mathrm{mg} / \mathrm{dL}$ for those at low to moderate CV risk.

In terms of primary prevention, all five countries (Table 1) recommended statins, although guidelines in Malaysia, Indonesia, and the Philippines also advocated CVD prevention through healthy lifestyle changes. Malaysian primary prevention strategies also involved identifying individuals who are likely to develop CVD and obtaining lipid profiles for them, in addition to formulating dietary and lifestyle recommendations specifically tailored for Malaysian patients [42]. For secondary prevention, most countries recommended the use of high-intensity statins, with the Thai guidelines recommending non-statins if the LDL-C goal was not achieved within 6 months. Unlike the most recent AHA/ACC and ESC/EAS guidance, few local guidelines recommended the use of PCSK9 inhibitors.
It should be noted that updated guidelines for the management of plasma lipid disorders are currently not available for Australia and thus have not been included in Table 2. Most Australian clinicians use either the US or European Union guidelines.

\section{Studies of lipid-lowering treatments conducted in the Asia-Pacific region}

Lipid-lowering treatments are an essential component of the guidelines for each of the countries being discussed. In order to assess the effectiveness of lipid-lowering treatments and lipid goal attainment by patients, a number of major international studies have been initiated. Several of these studies also collated data from countries in the Asia-Pacific region; these studies include CEPH EUS (pan-regional study of hypercholesterolemia) [51], DYSIS (hyperlipidemia in the setting of chronic statin treatment), DYSIS II (hyperlipidemia in patients with acute and stable CHD) [52], and PRIMULA (mixed plasma lipid disorders) [53].

In CEPHEUS, CV risk category and attainment goals for LDL-C were assessed according to the updated NCEP ATP III guidelines, which were in use when the study was conducted (moderately high risk: LDL-C $<130 \mathrm{mg} / \mathrm{dL}$; high risk: $\mathrm{LDL}-\mathrm{C}<100 \mathrm{mg} / \mathrm{dL}$; very high risk: $\mathrm{LDL}-\mathrm{C}<70 \mathrm{mg} /$ $\mathrm{dL})$. Among patients who were receiving lipid-lowering treatments in 29 countries, approximately half (49.4\%) achieved their recommended LDL-C level (54.8 and 22.8\% of patients at high or very high CV risk, respectively) [54]. The Asian patients (Fig. 3) included in CEPHEUS demonstrated similar levels of goal attainment $(49.1 \%)$ compared with patients from all 29 countries [51]; however, there were substantial differences in goal attainment across the Asian countries, with Hong Kong showing the highest proportion of patients at goal, at $82.9 \%$ (Fig. 3).

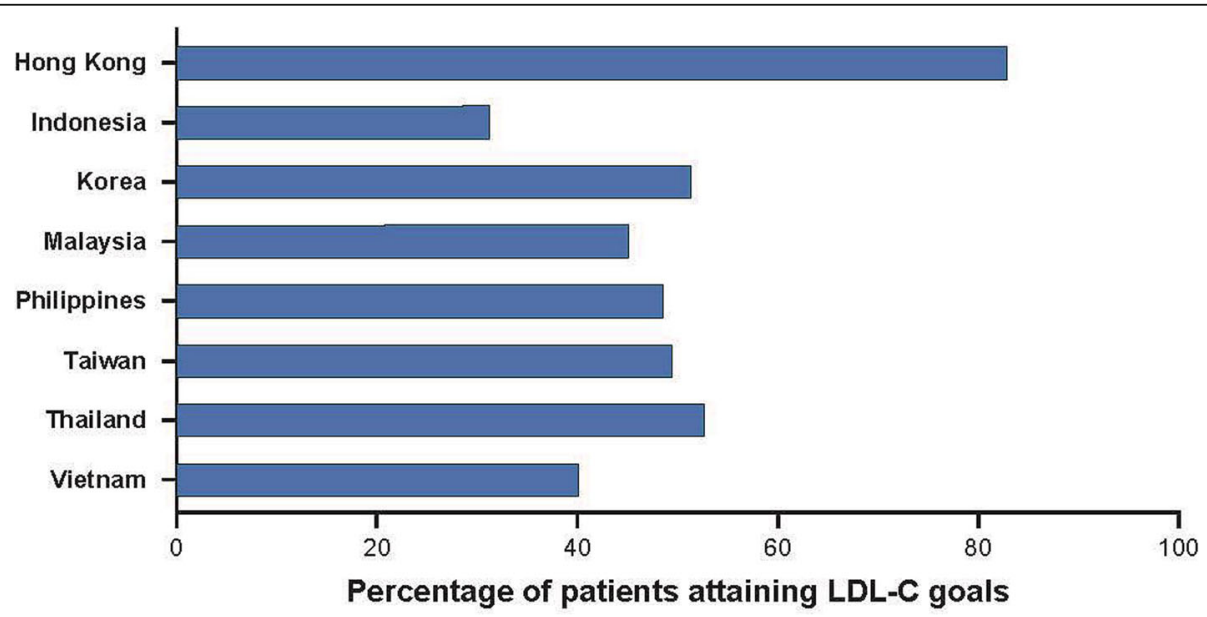

Fig. 3 Percentage of patients attaining LDL-C goals in Asian countries within the CEPHEUS study [51]. Abbreviation: LDL-C low-density lipoprotein cholesterol 
The attainment of LDL-C goals in Indonesia (31.3\%) [55] was below that of the overall rate in Asia (49.1\%), with the lowest attainment (12.1\%) found in patients with a therapeutic target of $<70 \mathrm{mg} / \mathrm{dL}$. Goal attainment was inversely related to $\mathrm{CV}$ risk and baseline LDL-C $(P<0.001)$. In Thailand [56], 52.7\% of patients reached their LDL goal (16.7\% in the very high risk group, $60.6 \%$ in the high risk group, and $84.7 \%$ in the moderately high risk group).

Variations in goal attainment between the Asian countries were thought to result from several factors, including differences in practice patterns and medication pricing [51]. The authors also reported that several factors were significantly associated with LDL-C goal attainment, including medication used, patient age, blood pressure, total cholesterol, and LDL-C levels at baseline, therapeutic LDL-C goals used, and compliance with treatment.

In DYSIS, CV risk category and attainment goals were based on ESC/EAS 2011 guidelines (moderate risk: LDL-C $<115 \mathrm{mg} / \mathrm{dL}$; high risk: LDL-C $<100 \mathrm{mg} / \mathrm{dL}$; very high risk: $\mathrm{LDL}-\mathrm{C}<70 \mathrm{mg} / \mathrm{dL}$ ). Only $21.7 \%$ of very high risk statin-treated patients attained $<70 \mathrm{mg} / \mathrm{dL}$ LDL-C [57]. In DYSIS II, CV risk category and attainment goals were based on ESC/EAS 2011 guidelines for very high risk patients (LDL-C $<70 \mathrm{mg} / \mathrm{dL}$ ). Many patients across Asia at very high risk of CV events had an LDL-C level above the recommended target [52]. In patients with highest risk, those with manifest acute coronary syndrome, reduction of LDL-C remained low (41.7\%). The proportions of patients in Hong Kong, India, Indonesia, the Philippines, Singapore, South Korea, Taiwan, Thailand, and Vietnam attaining LDL-C $<70 \mathrm{mg} / \mathrm{dL}$ are shown in Fig. 4 [52].

In PRIMULA, CV risk category and attainment goals for LDL-C were assessed according to the updated NCEP ATP III guidelines (moderately high risk: LDL$\mathrm{C}<130 \mathrm{mg} / \mathrm{dL}$; high risk: LDL-C $<100 \mathrm{mg} / \mathrm{dL}$; very high risk: LDL-C $<70 \mathrm{mg} / \mathrm{dL}$ ). A pooled analysis was conducted across Malaysia, Korea, Hong Kong, Thailand, and the Philippines [53]. Lipid-modifying therapy reduced the prevalence of plasma lipid disorders, but a third of patients still failed to achieve target/normal levels [53]. Patient characteristics associated with attaining LDL-C goals included patient risk (higher probability for non-smokers, non-diabetics, and non-CVD), gender (higher probability for men), and country (higher probability in Korea, lower probability in Malaysia and the Philippines). In Thailand, after 12 months of lipid-modifying therapy, $21 \%$ of patients overall (26\% in high risk group) still failed to attain LDL-C goals [58]. Lower LDL-C level at baseline was a significant predictor of goal attainment.

A real-world study in Thailand reported that the proportion of patients not at LDL-C goal was $77.7 \%$ for patients with established atherosclerotic disease (goal: $<70 \mathrm{mg} / \mathrm{dL}$ ) and $43.0 \%$ for patients with multiple risk factors [59].

Based on the studies above, there is a disconnect between the proportion of patients with known plasma lipid disorders, those treated, and those whose lipid levels are controlled. Although the use of lipid-lowering therapy is common across the Asia-Pacific region, it is not used to its full potential, especially in very high risk patients [52, 60]. In order to develop more effective management strategies, a better understanding of the reasons for poor goal attainment is needed.

\section{Barriers to lipid goal attainment}

Based on the clinical experience of the authors, there are several barriers to the attainment of recommended lipid goals, with a number of obstacles common across countries. There appears to be a reluctance amongst physicians in the Philippines, Malaysia, Thailand [61, 62], and Vietnam to use high-dose and/or high-intensity statins, even for secondary prevention. The use of suboptimal doses of statins was well-characterized in several Asian countries in the DYSIS-II study [52]. Despite guideline recommendations, some physicians in Vietnam are also reluctant to prescribe high-dose statins due to concerns about side effects. In the Philippines, some physicians in rural areas lack awareness of the latest clinical guidelines and/or trials and are thus less confident in prescribing higher-dose statins to patients. In Malaysia, suboptimal secondary prevention in patients with pre-existing coronary artery disease has been partly ascribed to poor physician prescribing patterns and patient compliance [60]. High workloads for GPs and primary care physicians in Malaysia can lead to rushed consultations, making the formation of partnerships between patients and physicians for the management of CV risk difficult. Furthermore, the timing of follow-up visits is not standardized and is often 6-9 months after the first consultation.

Patient attitudes to disease and treatment may also be barriers to lipid goal attainment. In Malaysia and Vietnam, patients are concerned about the potential side effects of statins, as many are influenced by the wealth of information (and misinformation) on the internet and on social media. Some patients do not appreciate the importance of controlling hypercholesterolemia as the condition may not result in any appreciable symptoms. Patients in the Philippines, particularly those in rural areas, are often reluctant to seek medical care unless they develop symptoms. Instead, some patients prefer to use herbal supplements, which are often recommended as a cure-all by friends, relatives, or social media. Patients in Malaysia also had doubts about the efficacy of lipid-lowering treatments as they did not provide immediate symptomatic relief, in contrast to other types 


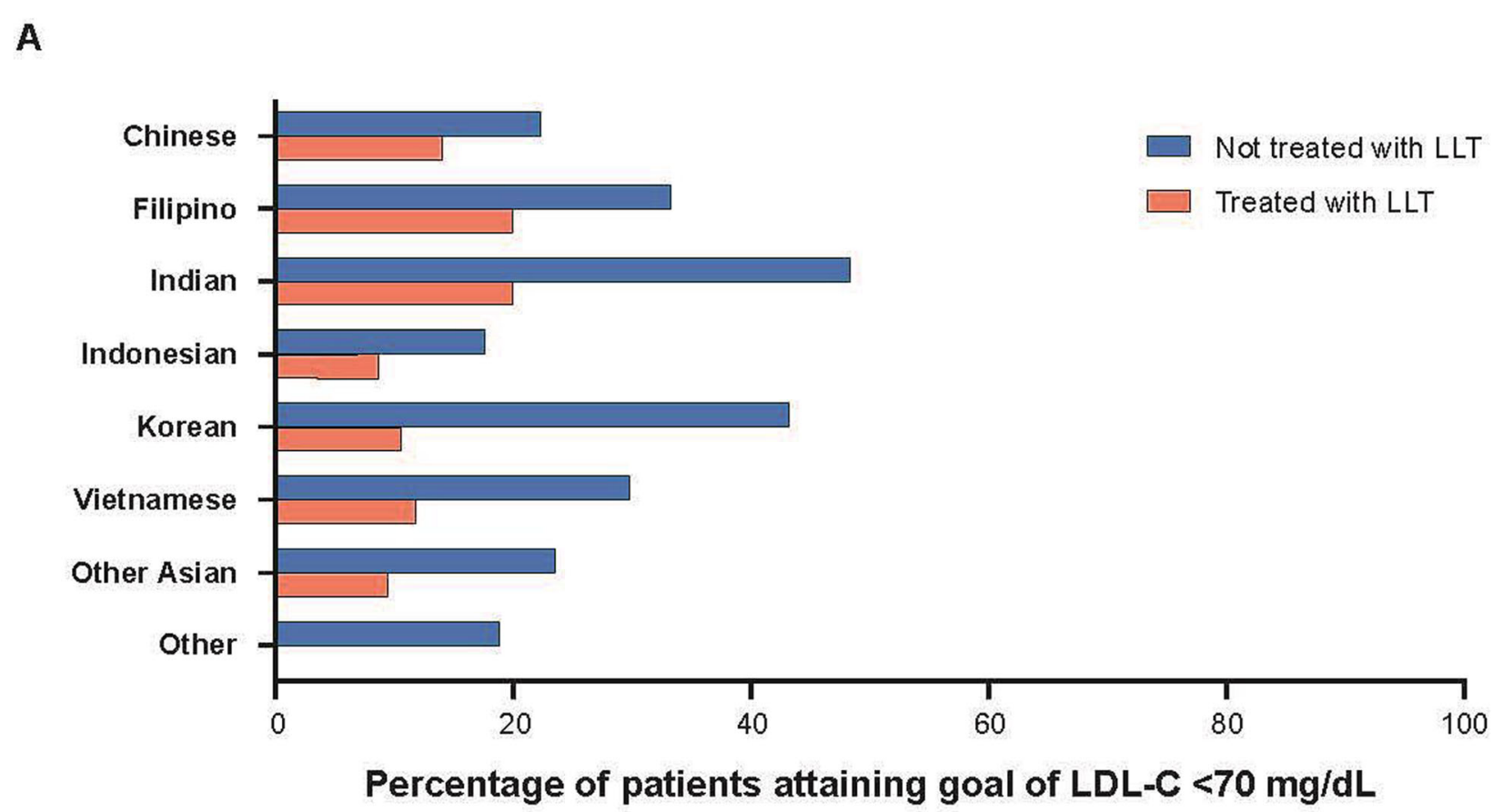

B

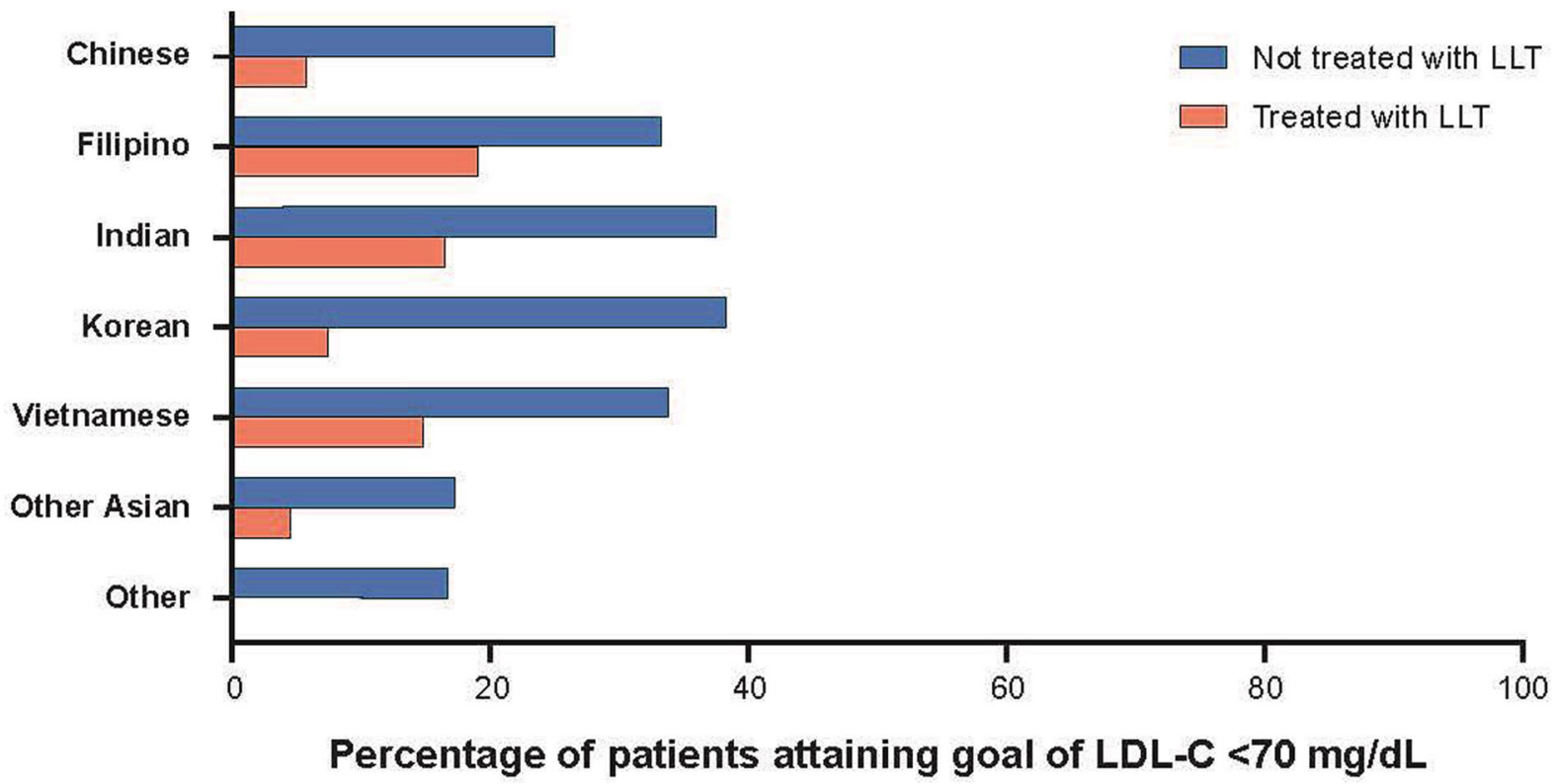

Fig. 4 Goal attainment (LDL-C $<70 \mathrm{mg} / \mathrm{dL}$ ) for Asian patients with $\mathbf{a}$ coronary heart disease and $\mathbf{b}$ acute coronary syndrome in the DYSIS-II study [52]. Abbreviations: LDL-C low-density lipoprotein cholesterol; LLT lipid-lowering therapies

of medications, such as analgesics. However, doubts concerning efficacy may not apply to all treatments; recent single-center studies in Italy suggest that the use of PCSK9 inhibitors may be associated with improved quality of life (as reported by patients) [63] and adherence to treatment [64]. It would be interesting to see if these findings also hold true for patients in the Asia-Pacific region.

The geographical make-up of the Philippines and Indonesia, with their populations spread across thousands of islands, poses unique challenges from a healthcare perspective. The management of $\mathrm{CV}$ risk and 
plasma lipid disorders can vary considerably from one area to another due to unequal distribution of healthcare resources. Populations in rural areas (e.g., mountainous areas and islands) face difficulties in accessing healthcare facilities, treatment, and healthcare workers. All these factors contribute to the low attainment of LDL-C goals in rural areas.

Until recently, healthcare funding has also been an issue in both Indonesia and the Philippines. However, the implementation of universal health coverage in Indonesia in 2014 [65] and the recent signing of the Universal Healthcare Act into law in the Philippines may ease some of the financial constraints for patients who would otherwise have to pay out of their own pocket (especially for medications for chronic conditions, such as diabetes, hypertension, and plasma lipid disorders in the Philippines). Despite the implementation of universal health coverage in most countries, the availability of some treatments may still be limited. In Indonesia, universal health coverage covers the cost of low- and moderate-intensity statins but not high-intensity statins. Therefore, patients who are prescribed high-intensity statins may be required to make out-of-pocket payments. This can result in physicians being reluctant to prescribe high-intensity statins or patients being unable to access statins of the appropriate intensity, leading to lower goal attainment. The low utilization of highintensity statins observed for several countries in this region is likely due to multiple factors. However, based on the data compiled for this review, it is difficult to definitively identify the factors specific to each country. As such, further research is needed to explore the reasons behind this important observation.

Although countries like Thailand have had universal health coverage for almost 20 years, the percentage of the population with high total serum cholesterol who are effectively treated remains small. Many of those affected are unaware of their condition, as reported in a 2004 study showing that $78 \%$ of affected individuals in Thailand were undiagnosed [66]. Although the proportion of undiagnosed patients in Thailand decreased in the following 10 years, $61.7 \%$ still remained undiagnosed according to the 2014 national health examination survey [38]. The underdiagnosis of high total cholesterol can be attributed to the general Thai population's lack of awareness about plasma lipid disorders or a failure to appreciate the importance of disease screening for the primary prevention of atherosclerotic CVD.

\section{Strengths and limitations}

The key strength of this review is the fact that it draws upon national survey data from each country of interest. Rather than focus on a specific subset of the population, national surveys generate data from a cross-section of the general population, capturing both affected and healthy individuals. For this reason, national survey data may provide a more accurate estimate of the true prevalence of lipid disorders in the general population, compared with specialized studies of prevalence. Another strength of the study is the country-specific, clinical experience of the authors, which provides valuable insights into the logistical, cultural, and regulatory issues faced by patients in each country. The main limitations of this review are the differences in the survey methods used in each country and the different thresholds used to categorize lipid disorders, which make direct comparisons between countries difficult. Nevertheless, the data presented provide a valuable snapshot of the current state of lipid disorders in the Asia-Pacific region.

\section{Conclusions}

Despite the widespread availability of both efficacious and well-tolerated lipid-lowering therapies and treatment guidelines, the prevalence of plasma lipid disorders is rising in the Asia-Pacific region. The clinical and economic impact of such an increase is likely to be substantial, given the age-adjusted mortality due to CVD being higher in many Asian countries than in Western countries. In the first of a planned series of publications focused on plasma lipid disorders in the Asia-Pacific region, this review highlights the prevalence of these disorders and defined several barriers to lipid goal attainment. Underdiagnoses, undertreatment, and suboptimal management of plasma lipid disorders is seen throughout the region, leading to poor goal attainment, even among those at high risk of CV events. In the future, improved approaches (as more information becomes available) need to be applied across the entire management continuum. Such approaches include improving screening for and diagnosis of plasma lipid disorders, increasing patient awareness and access to medications, and optimizing the use of lipid-lowering treatments. Improving adherence to therapeutic lifestyle changes and lipid-lowering therapy and the intensification of treatment to ensure that patients are treated to their appropriate LDL-C goal are also recommended for this region. In a future publication, the authors hope to expand upon some of these approaches in greater detail and discuss their possible impact.

\footnotetext{
Abbreviations

ACS: Acute coronary syndrome; ASCVD: Atherosclerotic cardiovascular disease; BMI: Body mass index; CABG: Coronary artery bypass grafting; CHD: Coronary heart disease; CKD: Chronic kidney disease; CV: Cardiovascular; CVD: Cardiovascular disease; DM: Diabetes mellitus; eGFR: estimated glomerular filtration rate; HbA1c: Glycated hemoglobin; HDL-C: High-density lipoprotein cholesterol; LDL-C: Low-density lipoprotein cholesterol; LLT: Lipid-lowering therapies; MI: Myocardial infarction; PCl: Percutaneous coronary intervention; TC: Total cholesterol; TG: Triglycerides; TLC: Therapeutic lifestyle changes
} 


\section{Acknowledgements}

Medical writing support was provided by Jon Edwards, PhD and Chu Kong Liew, PhD of Engage Scientific Solutions Ltd. and was funded by Pfizer Upjohn.

\section{Authors' contributions}

All authors participated in the analysis and interpretation of the data, and in the drafting, critical revision, and approval of the final version of the manuscript.

\section{Funding}

Medical writing support for this manuscript was funded by Pfizer Upjohn.

\section{Availability of data and materials}

The datasets supporting the conclusions of this article are included within the article.

\section{Declarations}

\section{Ethics approval and consent to participate}

Not applicable.

\section{Consent for publication}

Not applicable.

\section{Competing interests}

Zhen-Vin Lee has received honoraria from Aspen, AstraZeneca, Bayer, Boehringer Ingelheim, Merck, Merck Sharp \& Dohme, Novartis, Pfizer Upjohn, and Servier. Renan Sukmawan has received speaker's fees and honoraria for ad boards from AstraZeneca, Merck Sharp \& Dohme, Mitsubishi Tanabe Pharma, and Pfizer Upjohn. Nuntakorn Thongtang has received research funding from Pfizer Upjohn. Ho Huynh Quang Tri has received speaker's fees from Pfizer Upjohn, AstraZeneca, and Merck Sharp \& Dohme. Philip Barter has received honoraria for consultancies and ad boards from Pfizer Upjohn and Amgen. Elmer Llanes has received speaker's fees from AstraZeneca, Orient EuroPharma, Merck Sharp \& Dohme, and LRI-Therapharma.

\section{Author details}

${ }^{1}$ University Malaya Medical Centre, Kuala Lumpur, Malaysia. ${ }^{2}$ Division of Cardiovascular Medicine, University of the Philippines, Manila, Philippines. ${ }^{3}$ Department of Cardiology \& Vascular Medicine, Universitas Indonesia, National Cardiovascular Center Harapan Kita, Jakarta, Indonesia. ${ }^{4}$ Division of Endocrinology and Metabolism, Faculty of Medicine, Siriraj Hospital Mahidol University, Bangkok, Thailand. ${ }^{5}$ Heart Institute, Ho Chi Minh City, Vietnam. ${ }^{6}$ School of Medical Sciences, University of New South Wales, Sydney, NSW, Australia.

\section{Received: 19 August 2020 Accepted: 2 March 2021}

\section{Published online: 15 April 2021}

\section{References}

1. Ohira T, Iso H. Cardiovascular disease epidemiology in Asia: an overview. Circ J. 2013;77:1646-52.

2. Roth GA, Forouzanfar MH, Moran AE, Barber R, Nguyen G, Feigin VL, et al. Demographic and epidemiologic drivers of global cardiovascular mortality. N Engl J Med. 2015;372:1333-41.

3. Ritchie H, Roser M. Causes of death. 2019. https://ourworldindata.org/ca uses-of-death\#cardiovascular-disease. Accessed 8 Oct 2019

4. Roth GA, Johnson C, Abajobir A, Abd-Allah F, Abera SF, Abyu G, et al. Global, regional, and national burden of cardiovascular diseases for 10 causes, 1990 to 2015. J Am Coll Cardiol. 2017;70:1-25.

5. Alshamiri M, Ghanaim MMA, Barter P, Chang KC, Li JJ, Matawaran BJ, et al. Expert opinion on the applicability of dyslipidemia guidelines in Asia and the Middle East. Int J Gen Med. 2018;11:313-22.

6. Peters SAE, Wang $X$, Lam TH, Kim HC, Ho S, Ninomiya T, et al. Clustering of risk factors and the risk of incident cardiovascular disease in Asian and Caucasian populations: results from the Asia Pacific cohort studies collaboration. BMJ Open. 2018;8:e019335.

7. Nguyen HN, Fujiyoshi A, Abbott RD, Miura K. Epidemiology of cardiovascular risk factors in Asian countries. Circ J. 2013;77:2851-9.
8. Angkurawaranon C, Jiraporncharoen W, Chenthanakij B, Doyle P, Nitsch D. Urban environments and obesity in Southeast Asia: a systematic review, meta-analysis and meta-regression. PLoS One. 2014;9:e113547.

9. Collaboration NCDRF. Repositioning of the global epicentre of non-optimal cholesterol. Nature. 2020;582:73-7.

10. Chapman MJ, Ginsberg HN, Amarenco P, Andreotti F, Boren J, Catapano AL, et al. Triglyceride-rich lipoproteins and high-density lipoprotein cholesterol in patients at high risk of cardiovascular disease: evidence and guidance for management. Eur Heart J. 2011;32:1345-61.

11. Miller M, Stone NJ, Ballantyne C, Bittner V, Criqui MH, Ginsberg HN, et al. Triglycerides and cardiovascular disease: a scientific statement from the American Heart Association. Circulation. 2011;123:2292-333.

12. National Cholesterol Education Program Expert Panel on Detection, Evaluation, and Treatment of High Blood Cholesterol in Adults. Third report of the National Cholesterol Education Program (NCEP) expert panel on detection, evaluation, and treatment of high blood cholesterol in adults (adult treatment panel III) final report. Circulation. 2002;106:3143-421.

13. Aekplakorn W, Taneepanichskul S, Kessomboon P, Chongsuvivatwong V, Putwatana P, Sritara P, et al. Prevalence of dyslipidemia and management in the Thai population, National Health Examination Survey IV, 2009. J Lipids. 2014:2014:249584.

14. Rutherford JN, McDade TW, Feranil AB, Adair LS, Kuzawa CW. High prevalence of low HDL-c in the Philippines compared to the US: population differences in associations with diet and BMI. Asia Pac J Clin Nutr. 2010;19:57-67.

15. Grundy SM, Stone NJ, Bailey AL, Beam C, Birtcher KK, Blumenthal RS, et al. 2018 AHA/ACC/AACVPR/AAPA/ABC/ACPM/ADA/AGS/APhA/ASPC/NLA/ PCNA guideline on the Management of Blood Cholesterol: a report of the American College of Cardiology/American Heart Association task force on clinical practice guidelines. J Am Coll Cardiol. 2019;73:e285-350.

16. Mach F, Baigent C, Catapano AL, Koskinas KC, Casula M, Badimon L, et al. 2019 ESC/EAS guidelines for the management of dyslipidaemias: lipid modification to reduce cardiovascular risk. Eur Heart J. 2019;41:111-88,

17. Amiri M, Majid HA, Hairi F, Thangiah N, Bulgiba A, Su TT. Prevalence and determinants of cardiovascular disease risk factors among the residents of urban community housing projects in Malaysia. BMC Public Health. 2014; 14(Suppl 3):S3.

18. Hussain MA, Al Mamun A, Peters SA, Woodward M, Huxley RR. The burden of cardiovascular disease attributable to major modifiable risk factors in Indonesia. J Epidemiol. 2016;26:515-21.

19. Joshi SR, Anjana RM, Deepa M, Pradeepa R, Bhansali A, Dhandania VK, et al. Prevalence of dyslipidemia in urban and rural India: the ICMR-INDIAB study. PLoS One. 2014:9:e96808.

20. Khoo CM, Tan ML, Wu Y, Wai DC, Subramaniam T, Tai ES, et al. Prevalence and control of hypercholesterolaemia as defined by NCEP-ATPIII guidelines and predictors of LDL-C goal attainment in a multi-ethnic Asian population. Ann Acad Med Singap. 2013;42:379-87.

21. Khonputsa P, Veerman JL, Vos T, Aekplakorn W, Bertram M, Abbott-Klafter J, et al. Joint prevalence and control of hypercholesterolemia and hypertension in Thailand: third national health examination survey. Asia Pac J Public Health. 2012;24:185-94.

22. Kuwahara K, Uehara A, Yamamoto M, Nakagawa T, Honda T, Yamamoto S, et al. Current status of health among workers in Japan: results from the Japan epidemiology collaboration on occupational health study. Ind Health. 2016;54:505-14.

23. Lin $X, X u R$, Fang $L, C$ hen $W$, Hu D, Zhao $S$, et al. Factors influencing lowdensity lipoprotein cholesterol target achievement in primary care - results from DYSIS China. Int J Cardiol. 2016:222:51-6.

24. Liu M, Wang W, Ma L, Zhou M. Change on burden of diseases from hypercholesterolemia among the Chinese population from 1990 to 2010. Zhonghua Xin Xue Guan Bing Za Zhi. 2015;43:802-5.

25. Pokharel DR, Khadka D, Sigdel M, Yadav NK, Acharya S, Kafle R, et al. Prevalence and pattern of dyslipidemia in Nepalese individuals with type 2 diabetes. BMC Res Notes. 2017;10:146.

26. Suka M, Miwa $Y$, Ono $Y$, Yanagisawa $\mathrm{H}$. Changes in the prevalence of cardiovascular risk factors in Japanese workers during decade 2001-2011. Sangyo Eiseigaku Zassh. 2013:55:1-10.

27. Zaid M, Hasnain S. Plasma lipid abnormalities in Pakistani population: trends, associated factors, and clinical implications. Braz I Med Biol Res. 2018;51:e7239.

28. Zaman MM, Choudhury SR, Ahmed J, Talukder MH, Rahman AH. Blood glucose and cholesterol levels in adult population of Bangladesh: results from STEPS 2006 survey. Indian Heart J. 2016;68:52-6. 
29. Zhang FL, Xing YQ, Wu YH, Liu HY, Luo Y, Sun MS, et al. The prevalence, awareness, treatment, and control of dyslipidemia in Northeast China: a population-based cross-sectional survey. Lipids Health Dis. 2017;16:61.

30. Zhou JM, Luo XP, Wang S, Yin L, Pang C, Wang GA, et al. Prevalence and risk factors of dyslipidemia in a rural population of Henan Province, China. Zhonghua Yu Fang Yi Xue Za Zhi. 2016:50:799-805.

31. Punzalan FER, Sy RG, Sison OT, Castillo-Carandang NT, Gumatay A, Reganit PFM, et al. Prevalence of cardiovascular risk factors in relation to sociodemographic profile of the life course study in cardiovascular disease epidemiology study (LIFECARE) Philippine cohort. Acta Med Philipp. 2014;48: 62-9.

32. Sy RG, Morales DD, Dans AL, Paz-Pacheco E, Punzalan FE, Abelardo NS, et al. Prevalence of atherosclerosis-related risk factors and diseases in the Philippines. J Epidemiol. 2012;22:440-7.

33. Lin C-F, Chang $\mathrm{Y}-\mathrm{H}$, Chien S-C, Lin $\mathrm{Y}-\mathrm{H}$, Yeh H-Y. Epidemiology of dyslipidemia in the Asia Pacific region. Int J Gerontol. 2018;12:2-6.

34. Australian Bureau of Statistics. Australian health survey: biomedical results for chronic diseases, 2011-12. 2011. https://www.abs.gov.au/ausstats/abs@. nsf/lookup/4812278BC4B8FE1ECA257BBB001217A4?opendocument. Accessed 24 Sept 2019.

35. Ministry of Health of Republic of Indonesia. Basic Health Research. 2013. https://www.litbang.kemkes.go.id/laporan-riset-kesehatan-dasar-riskesdas/. Accessed 24 Sept 2019.

36. Ministry of Health Malaysia. National Health \& Morbidity Survey. 2015. http://www.moh.gov.my/moh/resources/nhmsreport2015vol2.pdf. Accessed 24 Sept 2019.

37. Food and Nutrition Research Institute (Philippines). 8th National Nutrition Survey Clinical and health survey. 2015. http://enutrition.fnri.dost.gov.ph/assets/ uploads/publications/Overview_8thNNS_050416.pdf. Accessed 20 Nov 2019.

38. National Health Examination Survey Office (Thailand). National Health Examination Survey V. 2014. http://thaitgri.org/?p=37869. Accessed 24 Sept 2019.

39. Ministry of Health: General Department of Preventative Medicine (Vietnam). National Survey on the risk factors of non-communicable diseases (STEPS) Viet Nam, 2015. 2015. https://www.who.int/ncds/surveillance/steps/VietNa m_2015_STEPS_Report.pdf. Accessed 24 Sept 2019.

40. Rugge B, Balshem H, Sehgal R, Relevo R, Gorman P, Helfand M. Screening and treatment of subclinical hypothyroidism or hyperthyroidism. Rockville: Agency for Healthcare Research and Quality (US); 2011.

41. Perhimpunan Dokter Spesialis Kardiovaskular Indonesia. Panduan Tata Laksana Dislipidemia 2017 [Indonesian heart association quidelines on Management of Dyslipidemia 2017]. 2017. http://www.inaheart.org/upload/ image/lipid.pdf. Accessed 13 Sept 2019.

42. Malaysian Ministry of Health. Management of Dyslipidaemia Guidelines 2017 (5th edition). 2017. http://www.moh.gov.my/moh/resources/Penerbitan/ CPG/CARDIOVASCULAR/4.pdf. Accessed 26 Nov 2018.

43. Guerrero AE. 2015 clinical practice guidelines for the Management of Dyslipidemia in the Philippines - executive summary: dyslipidemia guidelines 2015. ASEAN Heart J. 2016;24:7

44. The Royal College of Physicians of Thailand. 2016 RCPT clinical practice guideline on pharmacologic therapy of dyslipidemia for atherosclerotic cardiovascular disease prevention. 2016. http://www.thaiheart.org/downloa d/2016-RCPT-Dyslipidemia-Guideline.html. . Accessed 20 Nov 2019.

45. Vietnam National Heart Association. Recommendations on diagnosis and treatment of lipid disorders 2015. 2015. http://vnha.org.vn/cate.asp?cate_id=167. Accessed 24 Sept 2019

46. Kusmana D. The influence of smoking cessation, regular physical exercise and/or physical activity on survival: a 13 years cohort study of the Indonesian population in Jakarta. Med J Indonesia. 2002;11:230.

47. National Institute for Health and Care Excellence. Cardiovascular disease: risk assessment and reduction, including lipid modification. 2014. https://www. nice.org.uk/guidance/cg181. Accessed 20 Nov 2019.

48. Lau TW, Tan KEK, Choo JCJ, Ng TG, Tavintharan S, Chan JCN. Regional evidence and international recommendations to guide lipid management in Asian patients with type 2 diabetes with special reference to renal dysfunction. J Diabetes. 2018;10:200-12.

49. Selvarajah S, Kaur G, Haniff J, Cheong KC, Hiong TG, van der Graaf Y, et al. Comparison of the Framingham risk SCORE, SCORE and WHO/ISH cardiovascular risk prediction models in an Asian population. Int J Cardiol. 2014;176:211-8.

50. Faculty of Medicine, Ramathibodi Hospital, Mahidol University. Thai CV risk score. https://med.mahidol.ac.th/cardio_vascular_risk/thai_cv_risk_score/ tcvrs_en.html. Accessed 10 Dec 2019.
51. Park JE, Chiang CE, Munawar M, Pham GK, Sukonthasarn A, Aquino AR, et al Lipid-lowering treatment in hypercholesterolaemic patients: the CEPHEUS pan-Asian survey. Eur J Prev Cardiol. 2012;19:781-94.

52. Poh KK, Ambegaonkar B, Baxter CA, Brudi P, Buddhari W, Chiang FT, et al. Low-density lipoprotein cholesterol target attainment in patients with stable or acute coronary heart disease in the Asia-Pacific region: results from the dyslipidemia international study II. Eur J Prev Cardiol. 2018;25:1950-63.

53. Unniachan S, Bash LD, Khovidhunkit W, Sri RZ, Vicaldo E, Recto C 2nd, et al. Prevalence of lipid abnormalities and attainment of normal lipid levels among patients with dyslipidaemia: a pooled analysis of observational studies from five Asian countries. Int J Clin Pract. 2014:68:1010-9.

54. Chiang CE, Ferrieres J, Gotcheva NN, Raal FJ, Shehab A, Sung J, et al. Suboptimal control of lipid levels: results from 29 countries participating in the centralized pan-regional surveys on the Undertreatment of Hypercholesterolaemia (CEPHEUS). J Atheroscler Thromb. 2016:23:567-87.

55. Munawar M, Hartono B, Rifqi S. LDL cholesterol goal attainment in hypercholesterolemia: CEPHEUS indonesian survey. Acta Cardiol Sin. 2013; 29:71-81.

56. Sukonthasarn A, Homsanit M, Prommete B, Chotinaiwattarakul C, Piamsomboon C, Likittanasombat K. Lipid-lowering treatment in hypercholesterolemic patients: the CEPHEUS Thailand survey. J Med Assoc Thail. 2011:94:1424-34.

57. Gitt AK, Lautsch D, Ferrieres J, Kastelein J, Drexel H, Horack M, et al. Lowdensity lipoprotein cholesterol in a global cohort of 57,885 statin-treated patients. Atherosclerosis. 2016;255:200-9.

58. Khovidhunkit W, Silaruks S, Chaithiraphan V, Ongphiphadhanakul B, Sritara P,

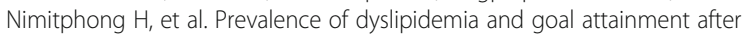
initiating lipid-modifying therapy: a Thai multicenter study. Angiology. 2012; 63:528-34.

59. Phrommintikul A, Krittayaphong R, Wongcharoen W, Yamwong S, Boonyaratavej S, Kunjara-Na-Ayudhya $\mathrm{R}$, et al. Management of atherosclerosis risk factors for patients at high cardiovascular risk in realworld practice: a multicentre study. Singap Med J. 2017;58:535-42.

60. Abdul Hafidz MI, Zainudin LD, Lee Z-V, Hadi MF, Mahmood Zuhdi AS. Secondary prevention patterns in persons with pre-existing coronary artery disease: are we getting it right? Proc Singapore Healthc. 2018;27:157-61.

61. Chinwong D, Patumanond J, Chinwong S, Siriwattana K, Gunaparn S, Hall J, et al. Statin therapy in patients with acute coronary syndrome: low-density lipoprotein cholesterol goal attainment and effect of statin potency. Ther Clin Risk Manag. 2015;11:127-36

62. Lee B, Dumrongkitchaiporn K, Sriussadaporn S, Thongtang N. Statin intensity regimens in thai type 2 diabetic patients who achieved LDL-C targets. J Med Assoc Thail. 2017;100:603.

63. Cesaro A, Gragnano F, Fimiani F, Moscarella E, Diana V, Pariggiano I, et al. Impact of PCSK9 inhibitors on the quality of life of patients at high cardiovascular risk. Eur J Prev Cardiol. 2020;27:556-8.

64. Gragnano F, Natale F, Concilio C, Fimiani F, Cesaro A, Sperlongano S, et al. Adherence to proprotein convertase subtilisin/kexin 9 inhibitors in high cardiovascular risk patients: an Italian single-center experience. J Cardiovasc Med (Hagerstown). 2018;19:75-7.

65. Agustina R, Dartanto T, Sitompul R, Susiloretni KA, Suparmi, Achadi EL, et al. Universal health coverage in Indonesia: concept, progress, and challenges. Lancet. 2019:393:75-102.

66. Roth GA, Fihn SD, Mokdad AH, Aekplakorn W, Hasegawa T, Lim SS. High total serum cholesterol, medication coverage and therapeutic control: an analysis of national health examination survey data from eight countries. Bull World Health Organ. 2011;89:92-101.

\section{Publisher's Note}

Springer Nature remains neutral with regard to jurisdictional claims in published maps and institutional affiliations. 